\title{
Formação Docente no Ensino Superior: Relevância da Formação Stricto Sensu
}

\section{Professor Graduation in Higher Education: Relevance of Stricto Sensu Graduation}

\author{
José Victor Pronievicz Barreto*a; Luiz Fernando Coelho da Cunha Filhoa; Fabíola Cristine de Almeida Rego ${ }^{\mathrm{a}}$
}

aUnopar, Programa de Pós Graduação Stricto Sensu em Saúde e Produção Animal. PR, Brasil.

*E-mail: jose.proni@hotmail.com

\begin{abstract}
Resumo
Este trabalho aborda a formação docente no Ensino Superior e objetiva, através de pesquisa bibliográfica, abordar sobre a formação do professor universitário, seus principais aspectos e relevâncias, como a trajetória de formação, as concepções de docência, o conhecimento pedagógico e a legislação brasileira e a docência. O professor desempenha função primordial na formação de outros profissionais, sendo assim, sua própria formação reflete diretamente em seus alunos e, por conseguinte, no desenvolvimento e estruturação dos futuros profissionais. Na trajetória de formação do docente é necessário compreender as relações existentes e mútuas entre o domínio do saber (conhecimento científico) e do saber fazer (conhecimento prático), uma vez que o acúmulo de títulos e conhecimentos não compõe um professor universitário de excelência, a prática docente deve objetivar a formação de saberes, a capacitação, o desenvolvimento de habilidades e competência dos alunos, e por fim, a formação de profissionais. Construída ao longo da carreira profissional, a formação do professor universitário vai além dos programas de graduação e pós-graduação convencionais, extrapolando-se para um contexto de aprendizagem que envolve conhecimentos teóricos e práticos obtidos na vivência diária dentro da Instituição de Ensino, englobando os alunos, demais professores e a sociedade como um todo.
\end{abstract}

Palavras-chave: Docência. Educação Superior. Professor Universitário.

\begin{abstract}
This work deals with teacher education in higher education and aims, through bibliographic research, to address the formation of the university professor, its main aspects and relevance, such as the formation trajectory, teaching conceptions, pedagogical knowledge and Brazilian legislation and teaching. The teacher plays a fundamental role in the training of other professionals, and thus, their own formation reflects directly on their students, and therefore on the development and structuring of future professionals. In the teacher education trajectory, it is necessary to understand the existing and mutual relations between the knowledge domain (scientific knowledge) and know-how (practical knowledge), since the titles and knowledge accumulation does not make up a university professor of excellence, teaching practice should aim at the knowledge formation, training, students'skills and competence development, and, finally, the professionals fromation. Built throughout the professional career, the university professor training goes beyond conventional graduate and postgraduate programs, extrapolating to a learning context that involves theoretical and practical knowledge obtained in daily experience within the educational institution, encompassing the students, other teachers and the society.
\end{abstract}

Keywords: Teaching. College education. College professor.

\section{Introdução}

A prática pedagógica para a formação de professores universitários apresenta imensa dimensão e complexidade. Uma vez que não há mediação pedagógica específica para a formação de futuros docentes do Ensino Superior, o processo de profissionalização docente é inconsistente, apoia-se em atributos próprios ou em modelos de outros professores. A partir do momento que os profissionais assumem uma função docente, os conhecimentos são provenientes de um determinado campo científico e da prática de outra atividade profissional que não a do magistério superior. De acordo com Libâneo (2011), o professor universitário deve ter uma formação didático-pedagógica que norteie as relações entre o ensino e a aprendizagem. Por isto, a pós-graduação deveria fornecer as ferramentas metodológicas e os embasamentos epistemológicos necessários para a constituição de quadros de pesquisadores-docentes de alto nível, comprometidos com a realidade do país e a produção de conhecimentos nacionais socialmente relevantes.

Contrariamente ao disseminado, não há uma formação específica ou paradigma a ser seguido na formação do docente, ficando a formação deste profissional sujeita a iniciativas individuais e institucionais. Embora segundo Corrêa e Ribeiro (2013), a formação pedagógica não necessita ser obrigatória, mas induzida e incentivada nos critérios de avaliação dos programas de pós-graduação stricto sensu e nas diretrizes específicas das políticas para o Ensino Superior.

O professor desempenha função primordial na formação de outros profissionais, sendo assim, sua própria formação reflete diretamente em seus alunos e, por conseguinte, no desenvolvimento e estruturação dos futuros profissionais, que se formam nas Instituições de Ensino Superior. Logo, ressaltase a importância de confirmar a necessidade de investimento, 
sobretudo, nos Programas de Pós-graduação stricto sensu, em processos educativos que primem pelo desenvolvimento da criatividade dos professores e em sua formação específica (BARRETO; MARTÍNEZ, 2007), o que claramente também envolve a motivação tanto do discente, quanto do docente (COLARES et al., 2019).

No Brasil é cada vez maior o número de Instituições de Ensino Superior, o que leva a questionar como ocorre e quais os aspectos envolvidos na formação de docentes no Ensino Superior, e assim se busca uma reflexão que considere as interfaces entre pesquisa e formação docente.

Este artigo tem como objetivo abordar sobre a formação do professor universitário, seus principais aspectos e relevâncias, como a trajetória de formação, as concepções de docência, o conhecimento pedagógico e a legislação brasileira e a docência em face à formação stricto sensu.

\section{Desenvolvimento}

\subsection{Metodologia}

Utilizou-se a pesquisa bibliográfica através da leitura de livros e artigos, direcionando o desenvolvimento do trabalho sobre a formação docente no Ensino Superior. Realizou-se uma revisão na literatura científica para construir o embasamento teórico desta revisão a compor a discussão, através de livros, publicações em periódicos e as legislações nacionais. Google Scholar, Scielo, PubMed e Portal de Periódicos CAPES foram as bases de dados eleitas para a pesquisa de artigos. $\mathrm{O}$ conhecimento obtido por meio da pesquisa foi transcrito para este artigo de forma a contemplar os questionamentos sobre o tema, o que também contribuirá para novas pesquisas.

\subsection{Discussão}

\subsubsection{Trajetória de formação}

$\mathrm{Na}$ trajetória de formação do docente é necessário compreender as relações existentes e mútuas entre o domínio do saber (conhecimento científico) e do saber fazer (conhecimento prático), para então se obter avanços quanto às questões formativas (ISAIA; BOLZAN, 2004). Pelo fato de a formação de professores do Ensino Superior ser embasada em conhecimento científico, através de titulação e produção científica, muitas vezes, o conhecimento prático é negligenciado.

As fases da vida e da profissão que se sucedem, ao longo da vida do docente, representam a trajetória do profissional, que compreendem não somente o trajeto individual, mas também a sociedade em si (ISAIA, 2001, 2003a, 2003b,).

$\mathrm{Na}$ concepção dos professores, influenciados pelas imposições da academia e seus órgãos reguladores, a carreira docente depende da qualificação como pesquisadores científicos por meio dos cursos de pós-graduação stricto senso, e não obstante pela sua produção científica (ISAIA; BOLZAN, 2004). Tal fato agrava a negligência que assola as relações obrigatórias entre o domínio do conhecimento científico e do conhecimento prático para a constituição de um bom professor universitário.

Nesse sentido, a pesquisa científica é privilegiada no contexto do Ensino Superior, sobretudo, em instituições públicas de ensino, ficando o ensino em segundo plano e subjugado como simplesmente a transmissão de conhecimentos (SANTOS, 1997; CUNHA, 2001). A problemática da formação do professor universitário consiste na divisão destas duas instâncias, o ser pesquisador e ser professor (ISAIA; BOLZAN, 2004). Os programas de pósgraduação stricto sensu se configuram como uma importante fase para a formação pedagógica do professor universitário, pois qualifica-o para a prática docente (MASETTO, 2009; SOARES; CUNHA, 2010). Portando, ressalta-se que o ideal é a integração do professor e pesquisador em um mesmo indivíduo, alcançando o sublime profissional que detém o conhecimento científico e o conhecimento prático.

O processo de formação do professor de Ensino Superior é baseado nos conhecimentos prévios, conhecimentos adquiridos durante sua formação acadêmica e os conhecimentos adquiridos durante a prática pedagógica desenvolvida na rotina da Instituição de Ensino. Dessa forma, os professores se formam de acordo com as necessidades da vida e da profissão (ISAIA; BOLZAN, 2004). São assim denominados como sujeitos ativos, atores de sua própria trajetória profissional (MARCELO, 1997). Freitas e Souza (2018) afirmam que a pós-graduação deveria fornecer as ferramentas metodológicas e os embasamentos epistemológicos necessários para a constituição de quadros de pesquisadores-docentes de alto nível, comprometidos com a realidade do país e a produção de conhecimentos nacionais socialmente relevantes.

Logo, o conhecimento pedagógico é obtido nas atividades do cotidiano, reflexo do conhecimento sobre o campo científico desenvolvido ao ministrar uma determinada disciplina e a forma que o docente se apropria da sua função de mediador e organizador do ensino, o papel de professor propriamente dito (PÉRES GÓMEZ, 1990; MOLL, 1996; BOLZAN, 2001, 2002).

Diante do exposto, a trajetória de formação é constituída pela trajetória pessoal, profissional e demais eventos formativos e não exclusivamente dos títulos obtidos e ciência produzida ao longo da carreira docente, pois o professor deve obrigatoriamente ter competência pedagógica e científica.

Construída ao longo da carreira profissional, a formação do professor universitário vai além dos programas de graduação e pós-graduação convencionais, extrapolando-se para um contexto de aprendizagem que envolve conhecimentos teóricos, científicos e práticos obtidos na vivência diária dentro da Instituição de Ensino, englobando os alunos, demais professores e a sociedade como um todo, tratando-se, portanto de um processo multi e interdisciplinar e que ocorre na conexão entre ensinar a aprender. 


\subsubsection{Concepções de docência}

A concepção de docência é condicionada pela dinâmica trajetória de formação da carreira docente, englobando os processos reflexivos, uma vez que os professores transformam o pensamento em palavras, as práticas efetivas (ISAIA; BOLZAN, 2004), e não obstante, por expectativas, sentimentos e apreciações (ISAIA, 2003b), ou seja, ultrapassa o espaço técnico, científico e teórico, permeando campos do afeto e da filosofia.

Os sentimentos fazem parte da construção do professor, atribuindo razão profissional e pessoal à docência, por ser um exercício continuado, a concepção abrange o conhecimento, sabedoria e ação (BARRETO; MARTÍNEZ, 2007; COLARES et al., 2019).

Logo, as experiências e conhecimentos ao longo do exercício da atividade docente, assim como tudo o que permeia, como a individualidade e contexto social no qual se insere o profissional, estabelece a verdadeira concepção de docência.

\subsubsection{O conhecimento pedagógico}

Nesse processo de formação, em que se ensina e se aprende, o conhecimento pedagógico, em sua amplitude, abrange o domínio de estratégias pedagógicas, do conhecimento teórico e conceitual, e suas inter-relações (MARCELO, 1997). Sendo assim, pode-se afirmar que o conhecimento pedagógico é construído no compartilhamento, pois resulta de trocas cognitivas e socioculturais entre o professor e seus alunos.

Portando, além do domínio de um campo específico da ciência, no qual o profissional é atuante, o conhecimento pedagógico incorpora uma extensão de fatores, que segundo Isaia (2002, 2003a, 2003b): "Compreende a sensibilidade frente ao aluno, a valorização dos saberes da experiência, a ênfase nas relações interpessoais, a aprendizagem compartilhada, a integração teoria/prática e o ensinar focado no processo de aprender do aluno".

Como o estatuto epistemológico e metodológico da Educação Superior é totalmente diferente do Ensino Básico, o professor deve levar em conta essa particularidade para a boa execução da prática docente. A Universidade tem sua própria cultura epistemológica, compreendendo e manifestando a teoria de forma ativa, pois suas normas educacionais têm propósitos tanto sociais quanto cognitivos, representadas por reuniões docentes que regulamentam a transposição do conhecimento científico por meio da organização das práticas pedagógicas de maneira organizada e sistematizada (BOLZAN, 2001, 2002). Estes eventos, ainda que aparentemente de cunho discente, compõem também a formação do professor.

Não obstante, tão importante como outros quesitos, o conhecimento teórico e prático do campo científico específico é fundamental na construção do conhecimento pedagógico para que a aula universitária permita ao aluno a aquisição de conhecimentos, de competências e de habilidades
(GARNDER, 1999). Posto as três atividades fundamentais da Universidade, ensino, pesquisa e extensão, a formação pedagógica deve contemplar este três itens.

Diante disto, o professor, consciente de seu papel na formação de outros profissionais, deve compreender a docência como uma atividade educativa, e para isto, deve estabelecer ações estratégicas para obter êxito no processo de ensino e aprendizagem. Portanto, o processo de formação de docentes não deve, em hipótese alguma, ser negligenciado. Sendo assim, estudos acerca deste tema se justificam e são de grande valia.

\subsubsection{Legislação brasileira e a docência}

São diversas as atribuições do professor, porém, de acordo com a Lei $\mathrm{n}^{\circ}$ 9394/96, o artigo 13 designa as seguintes responsabilidades ao professor, o que torna claro o compromisso do professor com o ensino: participar da elaboração do projeto pedagógico, elaborar e cumprir o plano de trabalho, zelar pela aprendizagem dos alunos, estabelecer estratégias de recuperação para alunos de menor rendimento, ministrar dias letivos e horas-aula estabelecidos, participar integralmente dos períodos dedicados ao planejamento, à avaliação e ao desenvolvimento profissional (BRASIL, 1996).

Porém, no que tange o processo de formação de professores universitários, a Lei de Diretrizes e Bases da Educação, Lei no 9394/96, em seu artigo 66, estabelece que o docente universitário deve ser preparado prioritariamente nos programas de pós-graduação stricto sensu, ou seja, em programas de mestrado e doutorado. Estes programas, por sua vez, objetivam formar pesquisadores, em seus campos específicos, sem dispor da formação pedagógica. Por outro lado, a Resolução 3/99 da Câmara de Educação Superior exige a oferta de uma disciplina sobre metodologia de ensino nos cursos de pós-graduação lato sensu.

Diante disto, a formação dos docentes universitários fica sob responsabilidade das próprias Instituições de Ensino e regulamentadas pelo Governo, porém as políticas públicas não estipulam diretrizes para a formação pedagógica do professor do Ensino Superior. Sendo assim, a não regulamentação efetiva da formação docente assola o Ensino Superior no Brasil pela baixa qualificação profissional.

Entre leis e diretrizes, a competência pedagógica é evidenciada apenas no Plano Nacional de Graduação (PNG), porém esta por mais que seja abordada nos programas de pós-graduação, aperfeiçoa-se durante a trajetória do docente, no contexto da educação continuada e no compartilhamento entre docentes, ou seja, da rotina docente. De acordo com Fórum Nacional de Pró-Reitores de Graduação (FORGRAD, 2004, p77): “A dimensão do Projeto Pedagógico no interior do qual se complementará a capacitação docente evitará o isolamento científico do pesquisador, confinado em institutos monoepistêmicos".

Entre as metas do PNG se encontra a deliberação por orientar as agências de fomento à pós-graduação stricto 
sensu para além da formação de pesquisadores, ampliando a capacitação e formação, igualmente stricto sensu, dos docentes da graduação, instituindo programas de práticas pedagógicas e oferecendo aos alunos a prática da docência universitária.

Em consonância, Soares e Cunha (2010) atentam para a falta de exigência nas políticas públicas de uma formação para o professor da Educação Superior que contemple os saberes específicos da prática docente. Porém, os cursos se desenvolvem pelas linhas de pesquisa e áreas de concentração que representam os temas e linhas científicas, nos quais os pós-graduandos se debruçam e desenvolvem suas atividades (ZAMPROGNA, 2019).

Em face ao exposto, o professor além de portar o diploma e as titulações, deve dominar os conhecimentos pedagógicos e científicos. Cabe às Instituições de Ensino oferecer programas de educação continuada para que se cumpram as boas práticas pedagógicas no Ensino Superior e cabe aos docentes a procura por programas de pós-graduação stricto sensu que possibilitem o real conhecimento científico necessário para o exercício da docência de incontestável superioridade.

\section{Conclusão}

Conclui-se que a prática docente no Ensino Superior não é apenas uma questão de domínio de conteúdo, de expertise em um campo determinado, assim como os programas de pós-graduação stricto sensu constituem uma importante fase para a formação pedagógica do professor universitário, pois possibilita a qualificação da prática docente. Pode-se concluir também que no campo da pedagogia universitária, pesquisas futuras são necessárias para a compreensão da docência universitária e da formação de conhecimentos teóricos e práticos, assim como sua aplicação na rotina docente, no contexto de pesquisa, ensino e extensão. Ademais, além da formação de saberes, por parte do professor universitário, futuras pesquisas devem investigar a forma na qual este conhecimento é compartilhado e transposto ao aluno, uma vez que o acúmulo de títulos e conhecimentos não compõe um professor universitário de excelência, pois o âmago da docência universitária deve ser a formação de saberes, a capacitação, a ciência, e o desenvolvimento de habilidades e competência dos alunos, e por fim, a formação de profissionais.

\section{Referências}

BARRETO, M.O.; MARTÍNEZ, A.M.; Possibilidades criativas de professores em cursos de pós-graduação stricto sensu. Estud. Psicol., v. 24, n.4, p.463-473, 2007.

BOLZAN, D.P.V. Formação de professores: compartilhando e reconstruindo conhecimentos. Porto Alegre: Mediação, 2002.

BOLZAN, D.P.V. A construção do conhecimento pedagógico compartilhado: um estudo a partir de narrativas de professoras do ensino fundamental. Porto Alegre: UFRGS, 2001

BRASIL. Ministério da Educação. Resolução n. 3, de 5 de outubro de 1999. Fixa condições de validade de cursos presenciais de especialização. Brasília: MEC, 1999.
BRASIL. Ministério da Educação. Lei n. 9394, de 20 de dezembro de 1996. Estabelece as diretrizes e bases da educação nacional. Brasília: MEC, 1996.

COLARES, A.C.V. et al. Motivação docente na pós-graduação stricto sensu: uma análise a partir da teoria da autodeterminação. Rev. Contab. Finanças, v.30, n.81, p.381-395, 2019.

CORRÊA, G.T.; RIBEIRO, V.M.B. A formação pedagógica no ensino superior e o papel da pós-graduação stricto sensu. Educ. Pesq., v.39, n.2, p.319-334, 2013.

CUNHA, M.I. Ensino como mediação da formação do professor universitário. In: MOROSINI, M. (Org.). Professor do ensino superior: identidade, docência e formação. Brasília: Plano, 2001, p.79-92.

FORGRAD, Plano Nacional de Graduação: um projeto em construção. In: FORGRAD. Resgatando espaços e construindo ideias. Uberlância: Edufu, 2004, p.1-37.

FREITAS, M.F.Q.; SOUZA, J. Pensar a formação e a pesquisa na pós-graduação stricto sensu. Educar Rev., v. 34, n. 71, p. 9-18, 2018.

GIL, A.C. Métodos e técnicas de pesquisa social. São Paulo: Atlas, 2008.

ISAIA, S. Formação do professor de ensino superior: traumas na tessitura. In: MOROSINI, M. (Org.). Enciclopédia de pedagogia universitária. Porto Alegre: FAPERPGS/RIES, 2003a, p.241-251.

ISAIA, S. M. de A.; BOLZAN, D. P. V. Formação do professor do ensino superior: um processo que se aprende?. Rev. Educação (UFSM), v.29, n.2, p.121-133, 2004.

ISAIA, S. O professor de licenciatura, desafios para sua formação. In: SILVA, D; POLENZ, T. (Org.). Educação e contemporaneidade. Mudança de paradigma na ação formadora da Universidade. Canoas: ULBRA, 2002, p. 143-162.

ISAIA, S. O professor universitário no contexto de sua trajetória como pessoa e profissional. In: MOROSINI, M. (Org.). Professor do ensino superior. Identidade, docência e formação. Brasília: Plano, 2001, p. 35-60.

ISAIA, S. Professor de licenciatura: concepções de docência. In: MOROSINI, M. (Org.). Enciclopédia de pedagogia universitária. Porto Alegre: FAPERPGS/RIES, 2003b, p. 263-277.

LIBÂNEO, J.C. Conteúdos, formação de competências cognitivas e ensino com pesquisa. In: PIMENTA, S.G.; ALMEIDA, M.I. (Org.). Pedagogia universitária: caminhos para a formação de professores. São Paulo: Cortez, 2011. p. 188-212.

MARCELO, C. A formação de professores: novas perspectivas baseadas na investigação sobre o pensamento do professor. In: NÓVOA, A. (Coord.) Os professores e sua formação. Lisboa: Dom Quixote, 1997.

MASETTO, M.T. Professor universitário: um profissional da educação na atividade docente. In: MASETTO, M.T. (Org.) Docência universitária. Campinas: Papirus, 2009. p. 9-26.

MOLL, L.C. Vygotski e a educação. Porto Alegre: Artes Médicas, 1996.

SANTOS, L. Ensino como produção cultural: novas perspectivas para os currículos e formação de professores. In: LEITE, D.; MOROSINI, M. (Org.). Universidade futurante. Campinas: Papirus, 1997, p.125-133.

SOARES, S.R.; CUNHA, M.I. Programas de pós-graduação em educação: lugar de formação da docência universitária? Rev. Bras. Pós-Grad., v.7, n.14, p.577-604, 2010.

ZAMPROGNA, K.M. et al. Caracterização da formação didáticopedagógica em programas brasileiros de pós-graduação stricto sensuemenfermagem.Rev.Esc.Enferm. USP, v.53,n.1,p.1-6,2019. 